\title{
Deformation Mode Transitions in Amorphous-Cu45Zr55/Crystalline-Cu Multilayers
}

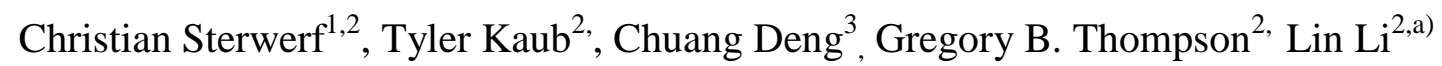 \\ ${ }^{1}$ Center for Spinelectronic Materials and Devices, Physics Department, Bielefeld University, 33615 \\ Bielefeld, Germany \\ ${ }^{2}$ Department of Metallurgical and Materials Engineering, The University of Alabama, Tuscaloosa, $A L$ \\ 35487, USA \\ ${ }^{3}$ Department of Mechanical Engineering, University of Manitoba, 15 Gillson Street, Winnipeg, MB, \\ R3T 5V6, Canada.
}

\begin{abstract}
:
A transition of deformation modes from shear banding to co-deformation subject to nanoindentation was revealed by a systematic experimental study of multilayers of amorphous-Cu45Zr55 (at/\%)/crystalline-Cu. The Cu45Zr55 was fixed at $150 \mathrm{~nm}$ where the $\mathrm{Cu}$ layers varied from $5 \mathrm{~nm}$ to $150 \mathrm{~nm}$. At the $5 \mathrm{~nm} \mathrm{Cu}$ layer thickness, the shear bands propagated through both layer types physically splitting the $\mathrm{Cu}$ layers. Upon increasing the $\mathrm{Cu}$ to $25 \mathrm{~nm}$, the shear bands were able to propagate through the amorphous layer but only locally bend the $\mathrm{Cu}$ layers. At the $150 \mathrm{~nm} \mathrm{Cu}$ layer thicknesses, the two phases co-deformed without clear evidence of shear propagation through the multilayer structure. Using molecular dynamics simulations, the spatial correlation of the shear transformation zones in the amorphous layers as a function of various $\mathrm{Cu}$ thicknesses was investigated. The simulations revealed a percolation created by the indent impression of the strain localization initiated in the amorphous layers above and below the $\mathrm{Cu}$ layer prior to shear banding. This spatial correlation condition was suspected to shear the $\mathrm{Cu}$ layer from both sides if the $\mathrm{Cu}$ layer is sufficiently thin.
\end{abstract}

\section{Key words:}

amorphous/crystalline multilayers, metallic glass, shear banding, co-deformation, shear transformation zone

\footnotetext{
a) Author to whom correspondence should be addressed. Electronic mail: $\underline{\text { lin.li @eng.ua.edu. }}$ Tel: +1-205-348-4971. Fax: +1-205-348-6419
} 


\section{Introduction}

Metallic glasses (MGs) are featured with their exceptional mechanical properties, e.g., high strength and hardness; but they suffer from negligible ductility due to strain localization and further shear banding which results in catastrophic failure [1, 2]. When crystalline phases are incorporated into the glassy matrix, these phases are able to mitigate the catastrophic shear band behaviors with improvements in plasticity and toughness [3-6]. This enhanced mechanical performance highlights the importance of interplay of distinct deformation mechanisms between the amorphous and crystalline phases. The coupled deformation behaviors hinge on the intrinsic material properties including crystalline, amorphous phase states, the crystalline-amorphous interface, the microstructural length scale setting by the inter-phase spacing, and the extrinsic loading conditions with respect to the interfaces. To delineate these factors in MG composites, the amorphous-crystalline multilayered structure presents a model system. The use of multilayers allows for a controlled growth of crystalline and amorphous phases and thus a systematic study of deformation behaviors [7-11]. Recent studies on such amorphous/nanocrystalline (e.g., $\mathrm{CuZr} / \mathrm{Cu}$ ) multilayers have revealed that when the layer thickness is carefully tuned, a multilayer structure can suppress the formation of catastrophic shear bands and enable plastic co-deformation of the two phases. In those investigations, the $\mathrm{CuZr}$ and $\mathrm{Cu}$ layers usually remained equal thickness, and thus the transition of deformation behaviors may emerge from the length scale effect of both amorphous and crystalline phases $[10,12]$. To date, the influence of the crystalline layer thickness on the shear band morphology of the amorphous phase has not yet been fully clarified and a subject of active research.

In this work, multilayers of amorphous $\mathrm{Cu} 45 \mathrm{Zr} 55$ (at/\%) and nanocrystalline $\mathrm{Cu}$ of varying thicknesses were grown and investigated in terms of shear band propagation. A transition of deformation modes from shear banding to co-deformation of the amorphous and crystalline phases was observed as the thickness of crystalline Cu layer increased from $5 \mathrm{~nm}$ 
to $150 \mathrm{~nm}$. This transition was signified by a diminishing of 'pop-in' or serrated flow events in the load-displacement curves for the nanoindentation tests. Further confirmation was noted by the deformation patterns around the indents themselves as viewed by scanning electron microscopy (SEM) images. To better understand the underlying deformation mechanisms for this transition, molecular dynamics (MD) simulations were employed, with particular emphasis on the roles played by the crystalline-amorphous interfaces to shear banding as the crystalline layer thickness varied.

\section{Experimental details}

The films were deposited in an ultra-high vacuum (UHV) dc-magnetron sputtering system with a base pressure of about $1 \times 10^{-8}$ Torr. The $\mathrm{Cu} 45 \mathrm{Zr} 55 / \mathrm{Cu}$ multilayers were grown from elemental $\mathrm{Cu}$ and $\mathrm{Zr}$ targets at room temperature on $\mathrm{Si}(100)$ substrates, with the top most layer always being $\mathrm{Cu}$ for each multilayer. Energy-dispersive $\mathrm{X}$-ray spectroscopy and X-ray reflectivity was performed to verify the stoichiometry and the film thickness, respectively. The total film thickness for all multilayers was about $4 \mu \mathrm{m}$ to minimize mechanical effects in the indent response from the substrate. In addition, the indent impression would also be from at least two bilayers based on the total film depth and the desire to indent at least $10 \%$ of the total film depth. effects during nanoindentation as well as to ensure that reasonable indentation data could be measured from at least two bilayers [13]. The thickness for the Cu45Zr55 layers was always fixed at $150 \mathrm{~nm}$, while the thickness of the $\mathrm{Cu}$ layers was $5 \mathrm{~nm}, 12.5 \mathrm{~nm}, 25 \mathrm{~nm}, 50 \mathrm{~nm}, 100 \mathrm{~nm}$ and $150 \mathrm{~nm}$, respectively.

Nanoindentation was conducted using an Agilent Nano Indenter G200 with a Berkovich diamond indenter tip of a radius $\leq 20 \mathrm{~nm}$. To measure the Young's modulus and the hardness, continuous stiffness measurements (CSM) were performed [14]. This technique superimposes a small oscillating force with small amplitude to the force of the tip. This provides an accurate and constant measurement of the contact stiffness. To image the microstructure of the indents, a dual beam Focus Ion Beam (FIB) with Field Emission Gun 
SEM (Tescan LYRA FIB-FESEM) was used. To look at the cross section of the deformed multilayer structure, both a FIB lift out transmission electron microscopy (TEM) foil and a SEM sub-surface viewing prospective was prepared. A thin Pt bar was deposited across the indent to prevent/reduce $\mathrm{Ga}^{+}$implantation damage into the film during milling. For the SEM imaging, a single trench was then milled normal to the Pt bar to reveal the layered structure and shear bands. For the TEM foil, a secondary trench was milled on the other side of the Pt bar where upon a thin foil under the bar was extracted using micro-manipulation. In both preparation methods, the cross section was ion polished with a low ion current and acceleration voltage to clean the surface from any milling damage that occurred at higher energy settings.

\section{Calculation}

To unveil the underlying mechanisms, the MD simulations of nanoindentation on $\mathrm{Cu} 45 \mathrm{Zr} 55 / \mathrm{Cu}$ multilayered structures were performed by using LAMMPS [15] with an embedded atom method potential for $\mathrm{Cu}-\mathrm{Zr}$ system developed by Mendelev et al. [16]. The simulated $\mathrm{Cu} 45 \mathrm{Zr} 55$ metallic glass was created by following a heating-and-quenching procedure [16]. The amorphous-crystalline multilayered structure was then constructed with alternating Cu45Zr55 (10 nm) and crystalline $\mathrm{Cu}$ layers $(2 \mathrm{~nm}$ and $10 \mathrm{~nm})$. Grain boundaries (GBs) perpendicular to the amorphous-crystalline interface (ACI) were also created in the crystalline $\mathrm{Cu}$ layer to make the simulation more realistic the experimentally synthesized microstructure. The width and thickness of the simulation box, i.e. the dimensions parallel to the ACI, was fixed, respectively, at $102 \mathrm{~nm}$ and $1.6 \mathrm{~nm}$ while the total height was 48 and 40 $\mathrm{nm}$, respectively, for the structure with 2 and $10 \mathrm{~nm} \mathrm{Cu}$ layer thicknesses. The MD simulation systems were smaller as compared to the experiments to accommodate a reasonable computational volume. As will be shown below, this smaller model system was found to be sufficient in capturing the deformation mode transitions that were helpful in understanding the experimental findings. The time step for the MD simulations was 5 fs. Periodic boundary 
conditions were applied along the directions parallel to the amorphous-crystalline plane while the sample surface (the direction perpendicular to the ACI) was kept free. Nanoindentation loading was simulated by moving a cylindrical virtual indenter of radius $R=40 \mathrm{~nm}$ at a constant velocity of $5 \mathrm{~m} / \mathrm{s}$ towards the sample surface [17]. Several atom layers at the bottom were fixed during the indentation. A canonical ensemble (NVT) was maintained during the indentation process with $\mathrm{T}=10 \mathrm{~K}$. Here the low temperature of $\mathrm{T}=10 \mathrm{~K}$ was chosen to ensure clear shear localization in the amorphous layer [17]. The use of the MD simulations provides the ability atomistically simulate potential deformation mechanisms. Though other forms of simulations, such as finite element methods, may provide a more precise stress distribution map, they require a priori knowledge of the deformation mechanism response to that stress. Here, we aim at using the simulations to lead the program into how single and/or multiple deformation mechanisms (shear banding, dislocation plasticity, and/or codeformation) develop in these layered structures in response to a reasonable representation of the stress state re-distribution created by indentation. In this manner, the simulations predictions can be compared to the experiments for validation and verification.

\section{Results}

\subsection{Materials characterization}

Fig. 1 shows X-ray diffraction scans for the pure $4 \mu \mathrm{m}$ thick Cu45Zr55 sample, the 4 $\mu \mathrm{m} \mathrm{Cu}$ layer and the various multilayers. The $\mathrm{Cu} 45 \mathrm{Zr} 55$ layers exhibited a diffuse peak near $2 \Theta=43.3^{\circ}$, confirming the amorphous structure. The thin $\mathrm{Cu}$ layers exhibited a strong $\{111\}$, fiber texture with minor $\{200\}$ and $\{220\}$ reflections noted as larger film thicknesses. 


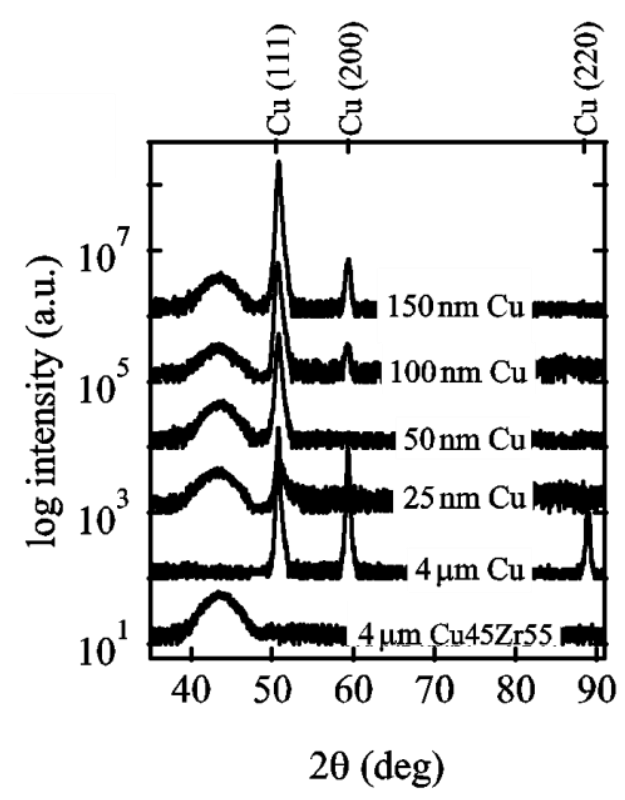

Fig. 1. XRD results of the multilayers, along with the $4 \mu \mathrm{m}$ crystalline $\mathrm{Cu}$ and the $4 \mu \mathrm{m}$ amorphous $\mathrm{Cu} 45 \mathrm{Zr} 55$ films for comparison.

\subsection{Mechanical responses subject to nanoindentation}

Fig. 2a shows representative load-displacement curves for the $4 \mu \mathrm{m}$ thick amorphous $\mathrm{Cu} 45 \mathrm{Zr} 55$ film along with the multilayers at $\mathrm{Cu}$ thicknesses of $5 \mathrm{~nm}, 12.5 \mathrm{~nm}, 25 \mathrm{~nm}, 50 \mathrm{~nm}$ $100 \mathrm{~nm}$ and $150 \mathrm{~nm} \mathrm{Cu}$ layers. Each measurement was taken at a strain rate of $0.01 \mathrm{~s}^{-1}$. As the thickness of the $\mathrm{Cu}$ layer increased, a transition from serrated to smooth responses was found. For the amorphous film, the load-displacement curve was serrated and featured discrete 'popin' events. The serrations of the amorphous film have been contributed to the formation and propagation of shear bands [2] which have been previously noted (and seen here but not shown) as steps in the pile up regions around the indent [18]. The load-displacement results for the multilayer with the $5 \mathrm{~nm} \mathrm{Cu}$ layers revealed a behavior very similar to that of the single amorphous Cu45Zr55 film's curve. At a Cu layer thickness of $12.5 \mathrm{~nm}$, less serrated flow was visible and the curve became smoother. Only a few "pop-in" events were visible. With increasing $\mathrm{Cu}$ layer thicknesses from $25 \mathrm{~nm}$ to $50 \mathrm{~nm}$ the number of displacement bursts decreased and the "pop-in" events become less pronounced. Thus, it was expected that near a Cu layer thickness of $25 \mathrm{~nm}$, the shear banding behavior changes in the $150 \mathrm{~nm}$ amorphous 


\section{Eu45Zr55 layer of the multillayer.}

The hardness data measured at $200 \mathrm{~nm}$ indentation depth are shown in Fig. 2b. The hardness decreased with increasing $\mathrm{Cu}$ layer thickness, i.e. $5 \mathrm{~nm}$ to $150 \mathrm{~nm}$, which can be generally attributed to the increased amount of softer $\mathrm{Cu}$ layers [7]. Interestingly, when the $\mathrm{Cu}$ layers were $5 \mathrm{~nm}$ and $12.5 \mathrm{~nm}$ thick, the hardness had a larger value than that of the single amorphous phase film. This augmentation can be directly related to with the shear banding behavior. When the $\mathrm{Cu}$ layer was very thin, shear bands can propagate through the $\mathrm{Cu}$ layer and continue deep into the sample [7]. These types of 'sheared $\mathrm{Cu}$ ' layers can serve as an additional obstacle along the shear band path, which would increase the hardness or difficulty to propagate the bands because of the extra energy necessary to shear though these particular crystalline layers.

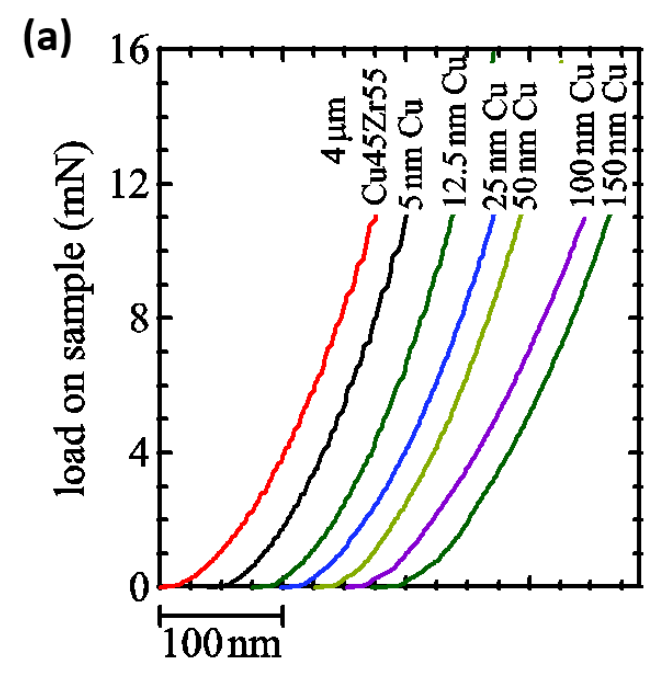

displacement into surface

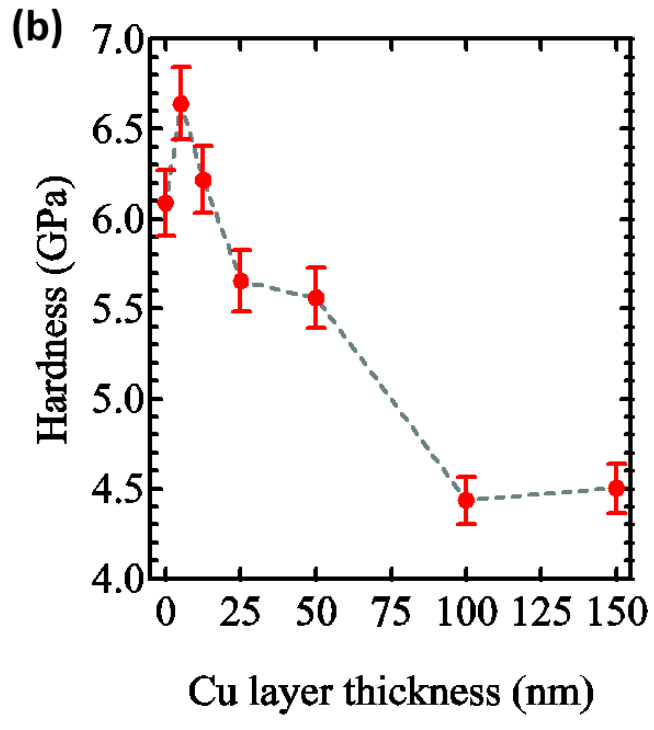

Fig. 2. (a) Load-displacement curves from nanoindentation measurements at a strain rate of 0.01 $\mathrm{s}^{-1}$ for the $4 \mu \mathrm{m}$ amorphous Cu45Zr55 film and for the multilayers with $5 \mathrm{~nm}, 12.5 \mathrm{~nm}, 25 \mathrm{~nm}, 50$ $\mathrm{nm}, 100 \mathrm{~nm}, 150 \mathrm{~nm}$ thick $\mathrm{Cu}$ interlayers. (b) Hardness for all multilayers and the $4 \mu \mathrm{m}$ amorphous $\mathrm{Cu} 45 \mathrm{Zr} 55$ film measured at a strain rate of $0.01 \mathrm{~s}^{-1}$.

\subsection{Deformation morphology}

Fig. 3a is a TEM image of shear bands in the sample for $5 \mathrm{~nm}$ thick $\mathrm{Cu}$ layers after indentation. One can clearly see that at this thinnest $\mathrm{Cu}$ layer thickness, the shear band 
physically separated the $\mathrm{Cu}$ layers and continued to propagate through the sample. Upon increasing the $\mathrm{Cu}$ layer thickness to $25 \mathrm{~nm}$, the $\mathrm{Cu}$ layers were no longer split but bent, evident by the arrows pointing to the localized deformation in the SEM micrograph of Fig. 3b. The inset images of Fig. 3b are regions next to and under the indent. Upon increasing the $\mathrm{Cu}$ layer thickness to $150 \mathrm{~nm}$, the $\mathrm{Cu}$ layers were neither broken nor locally bent in response to the shear band propagation and both phases appeared to co-deform, as shown in Fig. 3c. These microstructure responses are consistent with the serrated to continuous flow noted in the indentation responses in Fig. 2a. Thus, we concluded from these experiments a transition effect of Cu's influence on the shear band propagation.

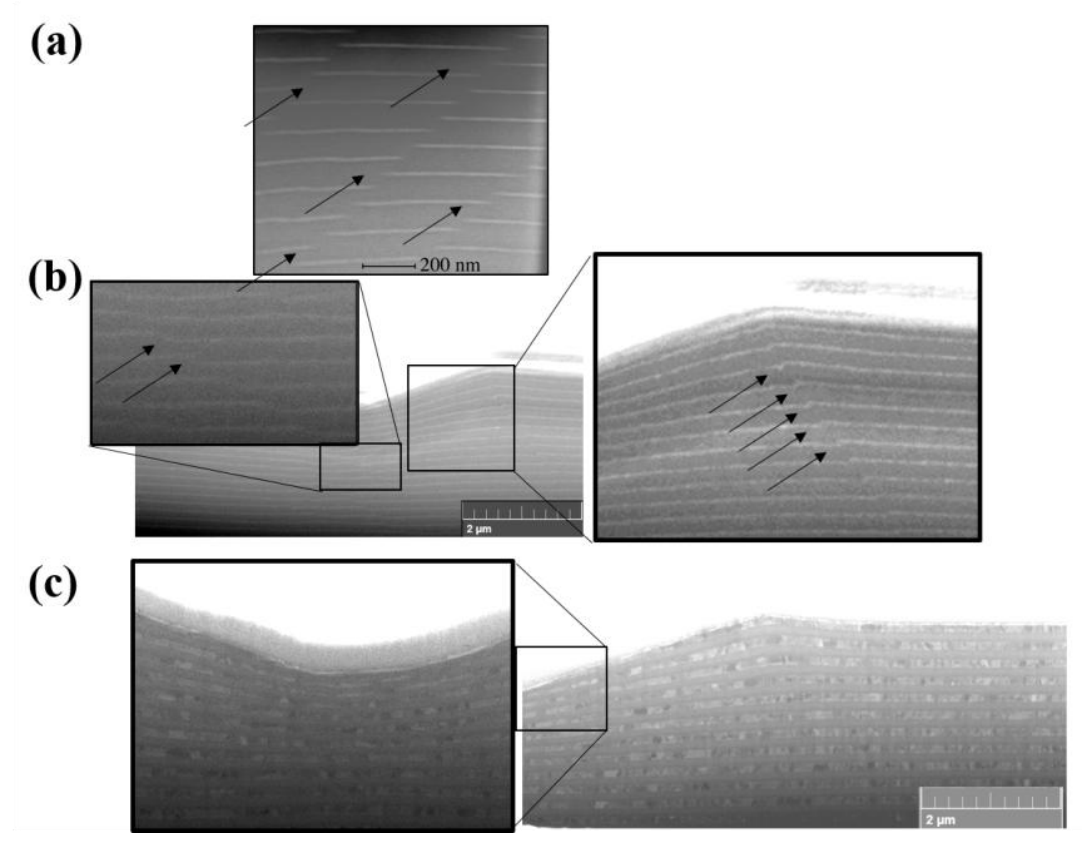

Fig.3. (a) The TEM image of a shear bands in the sample with $5 \mathrm{~nm}$ thick $\mathrm{Cu}$ interlayers underneath the indent. Note the arrows highlight the split in the $\mathrm{Cu}$ layers and location of the shear band. (b)The SEM cross sectional image of the indentation at the $25 \mathrm{~nm} \mathrm{Cu}$ layered sample. The magnified image near and under the indent reveal bent, but not broken, $\mathrm{Cu}$ layers indicated by the arrows. (c) The SEM cross sectional image of the $150 \mathrm{~nm} \mathrm{Cu}$ layered sample. Here, the $\mathrm{Cu}$ layer does not appear to be bent or sheared but undergoing continuous co-deformation with the amorphous phase.

\subsection{MD simulation results}

To understand this transition, a series of MD simulations were then performed and 
related to the experimental findings. As noted above, Thes these simulations are for slightly different layer thicknesses than the experiments-as noted above-because of computational limitations. Regardless of this difference, they still provide useful insights into the mechanisms that give rise to the transition. As can be seen in the simulation images of Fig. 4a and Fig. 4c, the plastic events in all multilayers were first initiated by shear transformation zones (STZs) in the top most amorphous layer. How the STZs propagate was found to be dependent on the $\mathrm{Cu}$ layer thickness, as noted in our experiments. For a $2 \mathrm{~nm} \mathrm{Cu}$ layer, the STZs became activated in the subsequent amorphous layers below the $\mathrm{Cu}$ layer before dislocations were nucleated in the crystalline layer. This can be seen by the highly localized strain region within that second amorphous layer but while the $\mathrm{Cu}$ layer was still intact above the region. Fig. $\mathbf{4 b}$ revealed that upon further indenting, the localized shear in the amorphous layers on either side of the $\mathrm{Cu}$ layer appeared to result in a spatial correlation that then lead to the shearing of the $\mathrm{Cu}$ layer and propagation of the shear bands. The propagation of the shear bands further into the film then followed the same behavior. This can be inferred from the highly localized shear strain seen in the amorphous layers on either side of the subsequent $\mathrm{Cu}$ layer.

Since GBs can also serve as stress concentrator and dislocation nucleation sources in polycrystalline metals, we added these features to our MD model. As can be seen in Fig. 4c, in the $10 \mathrm{~nm} \mathrm{Cu}$ layer, with the GBs highlighted by the arrows, no direct evidence of dislocation associated strain localization was observed to occur in these GBs upon indention. However, we do note the STZs were localized in the amorphous layers. Upon further indentation of the $10 \mathrm{~nm} \mathrm{Cu}$ layer, Fig. 4d, the onset of strain localization in the subsequent amorphous layer under the $\mathrm{Cu}$ layer was observed, as described in the preceding paragraph. However, it was significantly less than that observed for the thinner $2 \mathrm{~nm} \mathrm{Cu}$ layer simulation, Fig. 4b. For an equivalent indent depth between the $2 \mathrm{~nm}$ and $10 \mathrm{~nm} \mathrm{Cu}$ layers, the propagation of the shear bands was halted for the thicker $\mathrm{Cu}$ layer evident by the increased 
strain within the upper most amorphous layer and a reduction of such an effect in the subsequent layers below the $\mathrm{Cu}$ interlayer. This suggested that the $\mathrm{Cu}$ layers appeared to break down the spatial correlation of STZs along the shear path between the amorphous layers that were separated by the $\mathrm{Cu}$ interlayer.

The serrated-to-smooth transition, as shown in Fig. 2a, may be a result of the STZ events confined into the top few layers as the $\mathrm{Cu}$ thickness increased. The thick $\mathrm{Cu}$ layers can now act as a barrier to this spatial correlation of STZs at the ACIs and effectively block incipient shear bands, leading to smooth load-displacement curve.
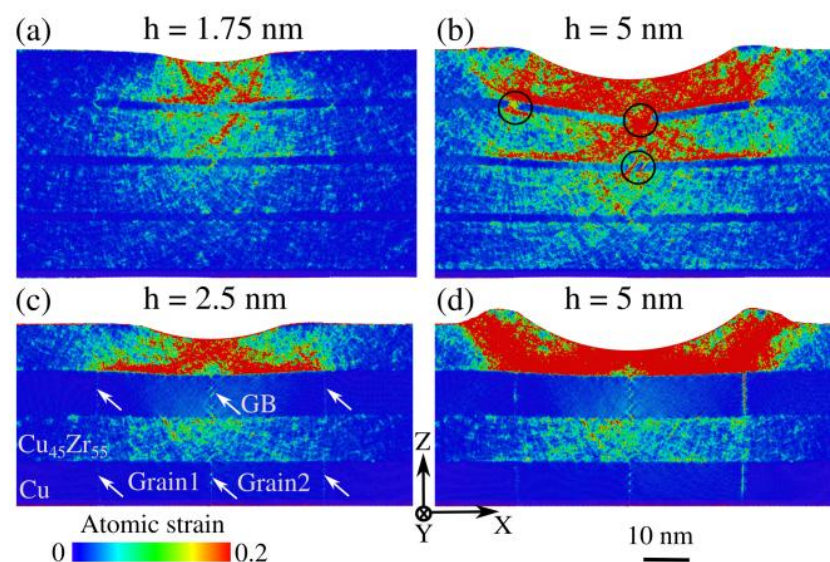

Fig. 4. (a) and (b) The atomistic configuration of the multilayer with $2 \mathrm{~nm} \mathrm{Cu}$ layer at indentation depth $\mathrm{h}=1.75 \mathrm{~nm}$ and $5 \mathrm{~nm}$, respectively. (c) and (d) The atomistic configuration of the multilayer with $10 \mathrm{~nm} \mathrm{Cu}$ layer at indentation depth $\mathrm{h}=2.5 \mathrm{~nm}$ and $5 \mathrm{~nm}$, respectively. The white arrows indicate the location of GBs in all $\mathrm{Cu}$ layers. The black circles highlight the plastic deformation in the $2 \mathrm{~nm} \mathrm{Cu}$ layer. The atom colors correspond to their local von Mises strain [19]. The orientations

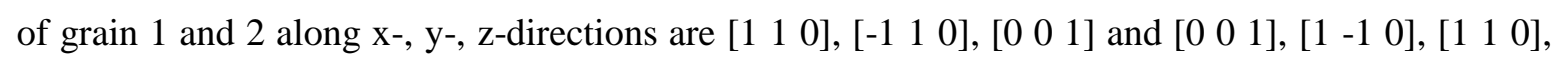
respectively.

\section{Discussion}

A semi-quantitative analysis of the transition of deformation modes was conducted via a comparison of the flow stress of multilayers with those of amorphous and crystalline $\mathrm{Cu}$ layers. The flow stresses of the multi-layered thin films were calculated as hardness normalized by a Tabor factor $\sim 2.7[18,20]$ with the results of which are-displayed in Fig 5. For the amorphous layer with a fixed thickness $=150 \mathrm{~nm}$, the flow stress was estimated from the hardness of $\mathrm{CuZr}$ amorphous film, i.e., $\sigma_{a m}=2.26 \mathrm{GPa}$, shown as the green dashed line in 
Fig. 5. Our estimation is in agreement with the reported values [21]. For the crystalline $\mathrm{Cu}$ layer with various thickness from $5 \mathrm{~nm}$ to $150 \mathrm{~nm}$, a layer-thickness dependence of the flow stress $\sigma_{C u}$ arises due to the confined dislocation slips between the ACIs. Consequently, $\sigma_{C u}$ can be estimated from the confined layer slipped (CLS) model [22] as shown below:

$$
\sigma_{C u}=M \frac{\mu^{*} b}{8 \pi h}\left(\frac{4-v}{1-v}\right) \ln \frac{\alpha t^{\prime}}{b}+\frac{\mu^{*} b}{L(1-v)}-\frac{f}{t_{C u}}
$$

where $M \sim 3.06$ is the Taylor factor of $\mathrm{Cu} . t^{\prime}=t_{\mathrm{Cu}} / \sin \phi$ is the thickness of the layer parallel to the glide plane, $\phi \sim 70.5$ the angle between the slip plane and the ACI. $b=0.2556 \mathrm{~nm}$ is the length of the Burgers vector. $v \sim 0.343$ is the Poisson ratio of $\mathrm{Cu}$. The effective shear modulus of the amorphous-crystalline multilayer $\mu^{*}=\left(\mu_{a m} * \mu_{C u}\right) /\left(V_{a m} * \mu_{C u}+V_{C u} \mu_{a m}\right)$ was calculated by the shear modulus $\left(\mu_{C u}\right)$ and volume fraction of the $\mathrm{Cu}$ layer $\left(V_{C u}\right)$ and those of the amorphous layer $\left(V_{a m}\right)$. The geometrical factor $\alpha=0.6$ representing the core cut-off parameter. $L=12.5 \mathrm{~nm}$, which is the mean spacing of glide loops in a parallel array. The characteristic interface stress of the amorphous-crystalline multilayers $f$ was chosen to be 0.6 $\mathrm{Jm}^{-2}$. Then the obtained thickness dependence of $\sigma_{C u}$ were plotted as the orange dashed line in Fig 5. Furthermore, the flow stress of multilayers was estimated using simple composite average:

$$
\sigma_{c o m p}=\sigma_{a m} \frac{t_{a m}}{t_{a m}+t_{C u}}+\sigma_{C u} \frac{t_{C u}}{t_{a m}+t_{C u}}
$$

the value of which was plotted as a blue solid line in Fig. 5

The composite flow stress $\sigma_{\text {comp }}$ of multilayers generally captured the trends of experimental data, e.g., decreasing flow stress with increasing $\mathrm{Cu}$ layer thickness. For multilayers with $5 \mathrm{~nm} \mathrm{Cu}$, the flow stress of amorphous layers was less than that of thin $\mathrm{Cu}$ 
layers $\left(\sigma_{\mathrm{am}}<<\sigma_{\mathrm{Cu}}\right)$, with the amorphous layers deformed by forming shear bands with a similar morphology to the monolithic amorphous film. The very thin $\mathrm{Cu}$ layers $\left(\sigma_{C u}=3.9\right.$ GPa) served as a strong barrier along the shear banding paths and eventually broke upon the formation of interlayer shear bands. This added extra strength to the multilayers and resulted in the highest hardness among all the films (including the amorphous CuZr film). Interestingly, the measured hardness of $5 \mathrm{~nm} \mathrm{Cu}$ multilayers was even larger than $\sigma_{\text {comp }}$ which accounts for the size effect of the $\mathrm{Cu}$ layers. This indicates that other strengthening mechanisms may also play roles, which will require further experimental investigation. $\mathrm{As} \mathrm{Cu}$ layer thickness increased to $15 \mathrm{~nm} \sim 25 \mathrm{~nm}, \sigma_{C u}$ decreased to $2.5 \mathrm{GPa} \sim 2 \mathrm{GPa}$, which was comparable to $\sigma_{\mathrm{am}}=2.26 \mathrm{GPa}$. The local stress concentration at the ACIs and the stress redistribution between the $\mathrm{Cu}$ and amorphous layers [23] can provide large internal stress to yield both layers. Consequently, interlayer shear bands may still form but reduced in severity, as the $\mathrm{Cu}$ layers can accommodate and block shear bands more effectively without breaking via sufficient dislocation activities. This then led to a smoother load-displacement curve (ref. to Fig 1a). When the $\mathrm{Cu}$ layer thickness further increased $>50 \mathrm{~nm}, \sigma_{\mathrm{Cu}} \sim 1.5 \mathrm{GPa}$, which was less than the amorphous flow stress, $<\sigma_{\mathrm{am}}$. Here the $\mathrm{Cu}$ layers dominated the plastic flow by their large dislocation activities. When the dislocations hit the ACIs, they may trigger correlated STZ activation from the ACIs which would result in plastic deformation in amorphous layers but without the formation of mature shear bands. This gave rise to the codeformation of the multilayers. As the $\mathrm{Cu}$ layer became thicker (i.e., > $100 \mathrm{~nm}$ ), the deformation of the multilayers was determined by $\sigma_{C u}$, and thus the experimentally extracted flow stress of multilayers was smaller than that of the $\sigma_{\text {comp }}$. This interpretation and-nicely follows the CLS model prediction. Consequently, the thickness dependence of flow stress of the $\mathrm{Cu}$ layer along with the discrepancy of flow stresses between the amorphous and $\mathrm{Cu}$ layers could contribute to the transition of deformation modes. 


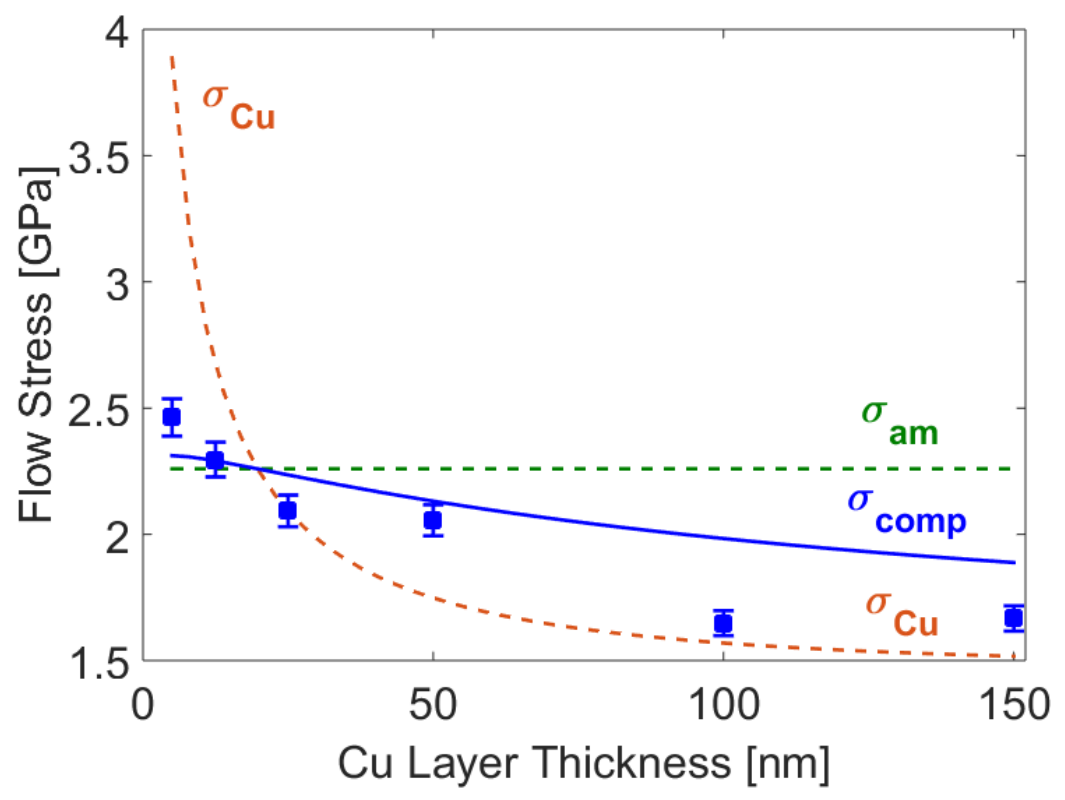

Fig. 5: Flow stress of multilayers as a function of $\mathrm{Cu}$ layer thickness. The data points were calculated from the measured hardness/2.7. The amorphous flow stress $\sigma_{a m}$ was estimated from the measured hardness of $\mathrm{CuZr}$ thin film/2.7. The flow stress of the crystalline $\mathrm{Cu}$ layers $\sigma_{C u}$ was calculated from confined layer slip (CLS) model (ref. to Eq 1). $\sigma_{c o m p}$ is a composite average of $\sigma_{a m}$ and $\sigma_{C u}$ according to Eq. 2 .

\section{Conclusions}

In summary, the systematic study of the role of different $\mathrm{Cu}$ layer thicknesses (5-150 $\mathrm{nm}$ ) in a fixed $150 \mathrm{~nm}$ layer thickness amorphous Cu45Zr55 multilayer revealed a suppression of shear band propagation. At $5 \mathrm{~nm} \mathrm{Cu}$ layer thicknesses, the shear bands were able to clearly separate the $\mathrm{Cu}$ layers. Upon increasing the $\mathrm{Cu}$ thickness to $25 \mathrm{~nm}$, the shear band was able to locally bend the $\mathrm{Cu}$ at the shear propagation locations but not physically split the $\mathrm{Cu}$ layer. Finally, at $150 \mathrm{~nm}$ of $\mathrm{Cu}$, the two phases co-deformed with no clear evidence of shear propagation through the multilayer structure. Using MD simulations, we were able to infer that upon indentation, strain localization formed in the uppermost amorphous layer and their progression is dependent on the mode of deformation of the $\mathrm{Cu}$ layer and its thickness. This creates a deformation-based transition. The MD simulations also 
revealed, for very thin $\mathrm{Cu}$ layers, that strain localization in the amorphous layer on either side of the $\mathrm{Cu}$ layer created a spatial correlation condition which sheared the $\mathrm{Cu}$ layer from both sides. If the $\mathrm{Cu}$ layer became sufficiently thick, it suppressed the formation and continual propagation of these shear bands further into the thickness of the multilayer and both layers co-deformed in response to the indentation load.

\section{Acknowledgements}

CS and GBT recognize the MINT International Fellowship Exchange. TK and GBT recognizes additional support from Army Research Office, grant W911NF1310436. LL acknowledges support through the U.S. Department of Energy (DOE), Office of Science, Basic Energy Sciences (BES) under Award DE-SC0016164. CS thanks Jan-Michael Schmalhorst and Günter Reiss for helpful discussions and funding support. The authors thank the Central Analytical Facility in the University of Alabama for access to the microscopy equipment.

\section{References}

[1] A.L. Greer, Y.Q. Cheng, E. Ma, Shear bands in metallic glasses, Mater. Sci. Eng. R-Rep., 74 (2013) 71-132.

[2] C.A. Schuh, T.C. Hufnagel, U. Ramamurty, Mechanical behavior of amorphous alloys, Acta Mater., 55 (2007) 4067-4109.

[3] D.C. Hofmann, J.-Y. Suh, A. Wiest, G. Duan, M.-L. Lind, M.D. Demetriou, W.L. Johnson, Designing metallic glass matrix composites with high toughness and tensile ductility, Nature, 451 (2008) 1085-1089.

[4] C. Fan, R.T. Ott, T.C. Hufnagel, Metallic glass matrix composite with precipitated ductile reinforcement, Appl. Phys. Lett., 81 (2002) 1020-1022.

[5] J. Qiao, H. Jia, P.K. Liaw, Metallic glass matrix composites, Mater. Sci. Eng. R-Rep., 100 (2016) 1-69.

[6] C.C. Hays, C.P. Kim, W.L. Johnson, Microstructure Controlled Shear Band Pattern Formation and Enhanced Plasticity of Bulk Metallic Glasses Containing in situ Formed Ductile Phase Dendrite Dispersions, Phys. Rev. Lett., 84 (2000) 2901-2904.

[7] W. Guo, E. Jägle, J. Yao, V. Maier, S. Korte-Kerzel, J.M. Schneider, D. Raabe, Intrinsic and extrinsic size effects in the deformation of amorphous $\mathrm{CuZr} /$ nanocrystalline $\mathrm{Cu}$ nanolaminates, Acta Mater., 80 (2014) 94-106.

[8] J.Y. Kim, D. Jang, J.R. Greer, Nanolaminates utilizing size-dependent homogeneous plasticity of metallic glasses, Adv. Funct. Mater., 21 (2011) 4550-4554.

[9] J.Y. Zhang, G. Liu, S.Y. Lei, J.J. Niu, J. Sun, Transition from homogeneous-like to shearband deformation in nanolayered crystalline $\mathrm{Cu}$ /amorphous $\mathrm{Cu}-\mathrm{Zr}$ micropillars: Intrinsic vs. extrinsic size effect, Acta Mater., 60 (2012) 7183-7196. 
[10] A. Donohue, F. Spaepen, R.G. Hoagland, A. Misra, Suppression of the shear band instability during plastic flow of nanometer-scale confined metallic glasses, Appl. Phys. Lett., 91 (2007) 241905.

[11] Y. Cui, O.T. Abad, F. Wang, P. Huang, T.-J. Lu, K.-W. Xu, J. Wang, Plastic Deformation Modes of CuZr/Cu Multilayers, Sci. Rep., 6 (2016) 23306.

[12] Y. Wang, J. Li, A.V. Hamza, T.W. Barbee Jr, Ductile crystalline-amorphous nanolaminates, Proc. Natl. Acad. Sci. U.S.A., 104 (2007) 11155-11160.

[13] American Society for Testing and Materials Annual Book of Standards 3.01, Standard test for mircohardness of materials ASTM Standard Test Method E 384, 1989.

[14] X. Li, B. Bhushan, A review of nanoindentation continuous stiffness measurement technique and its applications, Mater Charact., 48 (2002) 11-36.

[15] S. Plimpton, Fast Parallel Algorithms for Short-Range Molecular Dynamics, J. Comput. Phys., 117 (1995) 1-19.

[16] M.I. Mendelev, M.J. Kramer, R.T. Ott, D.J. Sordelet, D. Yagodin, P. Popel, Development of suitable interatomic potentials for simulation of liquid and amorphous $\mathrm{Cu}-\mathrm{Zr}$ alloys, Philos. Mag., 89 (2009) 967-987.

[17] C. Deng, C.A. Schuh, Atomistic mechanisms of cyclic hardening in metallic glass, Appl. Phys. Lett., 100 (2012) 251909.

[18] C.A. Schuh, T.G. Nieh, A survey of instrumented indentation studies on metallic glasses, J. Mater. Res., 19 (2004) 46-57.

[19] F. Shimizu, S. Ogata, J. Li, Theory of Shear Banding in Metallic Glasses and Molecular Dynamics Calculations, Materials Transactions 48 (2007) 2923-2927.

[20] D. Tabor, The hardness of solids, Review of Physics in Technology, 1 (1970) 145.

[21] Z.T. Wang, K.Y. Zeng, Y. Li, The correlation between glass formation and hardness of the amorphous phase, Scr Mater., 65 (2011) 747-750.

[22] A. Misra, J.P. Hirth, R.G. Hoagland, Length-scale-dependent deformation mechanisms in incoherent metallic multilayered composites, Acta Mater., 53 (2005) 4817-4824.

[23] A. Tekaya, T. Benameur, S. Labdi, P. Aubert, Effect of Ti/TiN multilayer protective nanocoatings on Zr-based metallic glasses mechanical performance, Thin Solid Films, 539 (2013) 215-221. 


\section{Figure Captions}

Fig. 1. XRD results of the multilayers, along with the $4 \mu \mathrm{m}$ crystalline $\mathrm{Cu}$ and the $4 \mu \mathrm{m}$ amorphous Cu45Zr55 films for comparison.

Fig. 2. (a) Load - displacement curves from nanoindentation measurements at a strain rate of $0.01 \mathrm{~s}^{-1}$ for the $4 \mu \mathrm{m}$ amorphous $\mathrm{Cu} 45 \mathrm{Zr} 55$ film and for the multilayers with $5 \mathrm{~nm}, 12.5 \mathrm{~nm}$, $25 \mathrm{~nm}, 50 \mathrm{~nm}, 100 \mathrm{~nm}, 150 \mathrm{~nm}$ thick $\mathrm{Cu}$ interlayers. (b) Hardness for all multilayers and the $4 \mu \mathrm{m}$ amorphous Cu45Zr55 film measured at a strain rate of $0.01 \mathrm{~s}^{-1}$.

Fig. 3. (a) The TEM image of a shear bands in the sample with $5 \mathrm{~nm}$ thick $\mathrm{Cu}$ interlayers underneath the indent. Note the arrows highlight the split in the Cu layers and location of the shear band. (b)The SEM cross sectional image of the indentation at the $25 \mathrm{~nm} \mathrm{Cu}$ layered sample. The magnified image near and under the indent reveal bent, but not broken, $\mathrm{Cu}$ layers indicated by the arrows. (c) The SEM cross sectional image of the $150 \mathrm{~nm} \mathrm{Cu}$ layered sample. Here, the $\mathrm{Cu}$ layer does not appear to be bent or sheared but undergoing continuous codeformation with the amorphous phase.

Fig. 4. (a) and (b) The atomistic configuration of the multilayer with $2 \mathrm{~nm} \mathrm{Cu}$ layer at indentation depth $\mathrm{h}=1.75 \mathrm{~nm}$ and $5 \mathrm{~nm}$, respectively. (c) and (d) The atomistic configuration of the multilayer with $10 \mathrm{~nm} \mathrm{Cu}$ layer at indentation depth $\mathrm{h}=2.5 \mathrm{~nm}$ and $5 \mathrm{~nm}$, respectively. The white arrows indicate the location of GBs in all $\mathrm{Cu}$ layers. The black circles highlight the plastic deformation in the $2 \mathrm{~nm} \mathrm{Cu}$ layer. The atom colors correspond to their local von Mises strain [19]. The orientations of grain 1 and 2 along x-, y-, z-directions are [ $\left.\begin{array}{lll}1 & 1 & 0\end{array}\right],\left[\begin{array}{lll}-1 & 1 & 0\end{array}\right],\left[\begin{array}{ll}0 & 0\end{array}\right.$ 0 1] and [0 [0 1], [ $\left.\begin{array}{lll}1 & -1 & 0\end{array}\right],\left[\begin{array}{lll}1 & 1 & 0\end{array}\right]$, respectively. 
Fig. 5: Flow stress of multilayers as a function of $\mathrm{Cu}$ layer thickness. The data points were calculated from the measured hardness/2.7. The amorphous flow stress $\sigma_{\mathrm{am}}$ was estimated from the measured hardness of $\mathrm{CuZr}$ thin film/2.7. The flow stress of the crystalline $\mathrm{Cu}$ layers $\sigma_{\mathrm{Cu}}$ was calculated from confined layer slip (CLS) model (ref. to Eq 1). $\sigma_{\text {comp }}$ is a composite average of $\sigma_{\mathrm{am}}$ and $\sigma_{\mathrm{Cu}}$ according to Eq. 2 . 